\title{
Putting physical activity in the 'must- do' list of the global agenda
}

\author{
Emmanuel Stamatakis (ㄷ) , ${ }^{1}$ Fiona C Bull (1) ${ }^{2,3}$
}

This special issue of BJSM celebrates the launch of the new 2020 WHO Global guidelines on physical activity and sedentary behaviour, an effort that took over 18 months and involved over 40 scientists and international collaboration across six continents. ${ }^{1}$ WHO guidelines reflect a consensus on the latest science on the health impacts of physical activity and sedentary behaviour across the age spectrum and, for the first time, cover important-but previously underservedpopulation groups: people who live with chronic disease or disabilities, and pregnant and postpartum women.

\section{THE NEW GUIDELINES: FORM FOLLOWS (EVIDENCE AND) FUNCTION}

As with any set of authoritative guidelines, these were based on a thorough review of a rapidly developing, yet very heterogeneous, body of evidence. The evidence was synthesised and evaluated for its quality and rigour following established WHO protocols. The outcome is a set of specific recommendations that form the new WHO guidelines based on the best evidence and informed by considerations of global applicability, feasibility and equity with the aim to optimise their use in national policy and local practice.

Evidence-based guidelines are more than just 'advice'; they serve a multitude of distinct but interrelated functions. First, guidelines represent a consensus of scientific knowledge following a transparent process and as such serve as a reference for national policy; gaps in knowledge are identified and thus they also provide as a guide for future research priorities. Recommendations are the basis for developing national communication campaigns and core health messages aimed at raising

${ }^{1}$ School of Health Sciences, Faculty of Medicine and Health, University of Sydney, Sydney, New South Wales, Australia

${ }^{2}$ Prevention on Noncommunicable Disease, Organisation Mondiale de la Sante, Geneve, Switzerland

${ }^{3}$ School of Human Science, The University of Western Australia, Perth, Western Australia, Australia

Correspondence to Professor Emmanuel Stamatakis, School of Health Sciences, University of Sydney, Sydney, NSW 2006, Australia;

emmanuel.stamatakis@sydney.edu.au awareness among diverse audiences, inspiring more physical activity in the community, and driving better physical activity prescription and policy. Recommended amounts of weekly amounts and frequency provide a yardstick by which national and global monitoring and surveillance systems can then track progress and evaluate whether physical activity policies are working at the population level.

We built this BJSM special issue having all these closely inter-related functions and purposes of guidelines in mind: scientific consensus, driver of research and practice, informing communication and messaging, mobilising interventions and monitoring progress.

\section{THE NEW GUIDELINES: IMPLICATIONS AND ACTION}

In the flagship paper of the special issue, the Guideline Development Group ${ }^{2}$ summarised details of the development process, consultation and recommendations for each age group and special population. In line with WHO focus on impact at the country level, this is a practical and action-oriented paper which concludes with an account of implications of these new guidelines on global policy, practice and health surveillance as well as highlighting issues surrounding guidelines communication. This theme of communication is picked up by Milton et $a l^{3}$ who detail a specific framework on how physical activity guidelines can and should effectively be communicated to reach their key audiences. The authors are clear about how a well-developed communications plan can maximise the impact of the new guidelines and analogous initiatives. The implications for national monitoring of trends in population levels of physical activity is addressed by Troiano et $a l^{4}$ who kick off with a challenging discussion acknowledging that long term health surveillance thrives on consistency and stability-which often contrasts with the needs to reflect changing science and guidelines evolution. Although there is no single solution, the future is likely to marry conventional surveillance tools with application of wearable technologies, assuming that the use of devices at scale will become universally affordable.

\section{GUIDELINES UNDERPIN GLOBAL ADVOCACY AND INVESTMENT}

Effective physical activity advocacy requires good arguments based on wellarticulated economic benefits. Using work productivity and excess mortality as their starting point, Hafner et $a l^{5}$ offer new ammunition to global physical activity advocacy by estimating potential global macro-economic benefits of increased physical activity from 2020 to 2050. Strengthening the economic case for investment to increase physical activity is a priority in all countries. However, often, the opportunities to be active are domainspecific. For example, through walking and cycling for transport-which Strain et $a l^{6}$ show is a predominant contributor to national levels of physical activity in large number of lower-income and middle-income country (LMIC). In their analysis of physical activity levels, the authors unpick for the first time at scale, the global domain-specific picture of the relative contribution of work, household, travel and leisure physical activity to national population levels of physical activity across 104 countries from six WHO regions. ${ }^{6}$ This provides an invaluable insight into where more investments and action on promoting physical activity should focus and a stimulus to global health researchers.

\section{HEALTH IMPACT OF PHYSICAL ACTIVITY AND SEDENTARY BEHAVIOUR}

One of the innovations in the new WHO guidelines is that it includes a combined physical activity and sedentary behaviour recommendation. ${ }^{2}$ This evidence on the interplay between physical activity and sedentary behaviour is mostly based on the findings from studies examining physical activity and sedentary behaviour independently from each other. ${ }^{7} \mathrm{New}$ data from Ekelund et $a l^{8}$ from a large harmonised meta- analysis examining joint associations of device-measured physical activity and sedentary time with all-cause mortality in 44000 adults from four countries. The conclusions of this study ${ }^{8}$ are likely to appeal to those who cannot fit hours of physical activity in their daily routines.

Leisure time physical activity is the most researched domain and such studies have shaped much of previous national and global guidance, while the health impacts of physical activity as part of one's work are often debated. ${ }^{9}$ Cillekens et $a l^{10}$ 
conducted a review of reviews on the associations of occupational physical activity and 23 health outcomes, including cancer, all-cause mortality and cardiovascular disease. While the main results confirm the benefits of occupational physical activity and caution regarding the potential harms of higher volumes of work-related activity, the authors also call for better quality research in this important domain.

\section{UNDER-REPRESENTATION OF LMICS: NOT JUST 'ANOTHER RESEARCH GAP'}

The evidence that informs the 2020 Global guidelines is derived largely from high income countries (HICs); only a small fraction of the global physical activity and sedentary behaviour research originated from LMIC. This is more than just 'another research gap'. There are large differences in how economies and societies are structured in LMIC countries, as well as a diversity of cultural norms and standards. Combined, these demand the development of physical activity evidence specific to these countries. For example, the majority of physical activity in LMIC is currently undertaken in the transportation and occupation domain, ${ }^{6}$ contrasting with the recreational domain in HICs. ${ }^{6}{ }^{10}$ Different political, cultural and competing healthcare priorities (such as the burden of infectious disease) influence how the guidelines should be tailored, communicated and monitored in LMICs contexts. In addition to contributing to the communication of the new guidelines, we hope that this special issue will ignite some much-needed discussion to increase investment in physical activity research and surveillance in LMICs.

\section{WHO 2020 GUIDELINES: A MEANS TO AN END, OR THE START OF A NEW BEGINNING?}

We hope that the material in this issue will not only inform and educate but will also be used as a call for action to policymakers, health professionals and other key audiences. Despite the efforts to date by various agencies, institutions and scientists, overall global progress on increasing population levels of physical activity has been slow and uneven. The publication of the new WHO global guidelines is timely. Disseminating the new guidelines effectively can accelerate implementation of the policy recommendations in the WHO's Global Action Plan on Physical Activity 2018-2030 and its ambitious target of $15 \%$ improvement by $2030 .^{11}$ This catalytic effect can be enhanced by the impacts of the COVID-19 pandemic which is rapidly transforming the world around us. Besides the magnitude of tragic consequences, the pandemic has opened unexpected opportunities to position and prioritise physical activity in the transportation $^{12}$ and health ${ }^{13}$ agendas of governments around the world. With careful communication, advocates can use these new guidelines to leverage these fertile circumstances and help achieve what over 40 years of science and advocacy have persistently strived for: to move physical activity policy from a 'nice to do' to a 'must-do', to support the health and wellbeing of peoples of all ages and walks of life. Let us all use these new Guidelines and work together towards this end!

Twitter Emmanuel Stamatakis@M_Stamatakis

Contributors ES drafted and redrafted the manuscript, FCB redrafted parts of the manuscript and approved the final version.

Funding The authors have not declared a specific grant for this research from any funding agency in the public, commercial or not-for-profit sectors.

Competing interests None declared.

Patient consent for publication Not required.

Provenance and peer review Not commissioned: internally peer reviewed.

(c) Author(s) (or their employer(s)) 2020. No commercial re-use. See rights and permissions. Published by BMJ.

\section{A) Check for updates}

To cite Stamatakis E, Bull FC. Br I Sports Med 2020:54:1445-1446.

Accepted 1 October 2020

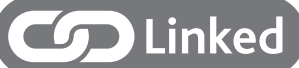

http://dx.doi.org/10.1136/bjsports-2020-103524

Br J Sports Med 2020:54:1445-1446.

doi:10.1136/bjsports-2020-103509
ORCID iDs

Emmanuel Stamatakis http://orcid.org/0000-00017323-3225

Fiona C Bull http://orcid.org/0000-0001-8035-4973

\section{REFERENCES}

1 World Health Organization. Global guidelines on physical activity and sedentary behaviour. Geneva: WHO, 2020.

2 Bull FC, Saad Al-Ansari S, Biddle S, et al. World Health organization 2020 guidelines on physical activity and sedentary behaviour. Br J Sports Med 2020;54. doi: 10.1136/bjsports-2020-102955.

3 Milton K, Bauman AE, Faulkner G, et al. Maximising the impact of global and national physical activity guidelines -the critical role of communication strategies. Br J Sports Med 2020;54. doi:10.1136/ bjsports-2020-102324.

4 Troiano RP, Stamatakis E, Bull F. How can global physical activity surveillance adapt to evolving physical activity guidelines? needs, challenges, and future directions. Br J Sports Med 2020;54. doi: 10.1136/ bjsports-2020-102621

5 Hafner M, Yerushalmi E, Stepanek M, et al. Estimating the global economic benefits of physically active populations over 30 years (2020 to 2050). Br J Sports Med 2020;54. doi:bjsports-2020-102590.

6 Strain T, Wijndaele K, Garcia L, et al. Levels of domainspecific physical activity at work, in the household, for travel and for leisure among 327,789 adults from 104 countries. Br J Sports Med 2020;54. doi:10.1136/ bjsports-2020-102601

7 Ekelund U, Tarp J, Steene-Johannessen J, et al. Dose-Response associations between accelerometry measured physical activity and sedentary time and all cause mortality: systematic review and harmonised meta-analysis. BMJ 2019;366:14570.

8 Ekelund U, Tarp J, Fagerland MW, et al. The joint associations of accelerometer measured physical activity and sedentary time with allcause mortality: a harmonized meta-analysis in more than 44,000 middle-aged and older individuals. Br J Sports Med 2020;54. doi: 10.1136/bjsports-2020-103270.

9 Shephard RJ. Is there a 'recent occupational paradox' where highly active physically active workers die early? Or are there failures in some study methods? $\mathrm{Br} J$ Sports Med 2019;53:1557-9.

10 Cillekens B, Lang M, van Mechelen W, et al. How does occupational physical activity influence health? an umbrella review of 23 health outcomes across 158 observational studies. Br J Sports Med 2020;54. doi:10.1136/bjsports-2020-102587.

11 World Health Organization. The global action plan on physical activity 2018-2030 (GAPPA): more active people for a healthier world. Geneva: World Health Organization, 2018.

12 UK Goverment Department for Transport. $£ 2$ billion package to create new era for cycling and walking: London: UK Goverment department for transport, 2020. Available: https://tinyurl.com/y9yry8wz [Accessed 30 Sep 2020].

13 Australian Government Department of Health. Exercising and staying active during coronavirus (COVID-19) restrictions, 2020. Available: https://tinyurl. com/yyrsc2td 